\title{
An SLM-model-based Empirical Study on the Coupling Induction between Technological Innovation-Oriented Resource Allocation and Trade Growth from the Perspective of Supply-side Management
}

\author{
You Yu Cong ${ }^{1, a}$, Yi Lu Xia ${ }^{2, b}$ \\ ${ }^{1}$ Guangzhou College of Business and Technology, Guangzhou 510850, China \\ ${ }^{2}$ Guangzhou College of Business and Technology, Guangzhou 510850, China \\ astoneyyc@163.com, ㅎ1070262@qq.com,
}

Keywords: technological innovation drive; coupling induction; SLM-model; supply side management; resource allocation.

Abstract. The optimal allocation of resources driven by technological innovation not only optimizes the spatial structure of foreign trade economic system, but also promotes the expansion of trade economy through technological innovation-driven resource allocation optimization. The technological innovation-driven resource allocation optimization is a kind of connotative spatial optimization growth mode and realization path of trade supply-side management. Therefore, this paper analyzes the allocation and changes of technological innovation-driven resources by analyzing the technological innovation-drive, based on the innovative knowledge resources, innovative human resources, innovative material resources and innovative financial resources. Aiming to study the coupling induction between resource allocation and foreign trade transformation and upgrading, the SLM empirical model is established and applied to conduct the present study. It is found that the optimal allocation of resources driven by technological innovation beholds a significant positive driving coupling induction effect on the upgrading of trade structure. According to the above analysis and quantitative research found in the existing problems, countermeasures and suggestions are rendered for trade transformation and upgrading by means of technological innovation-driven resource allocation optimization.

\section{Introduction}

The competitiveness of trade has always been the focus of academic and business attention. Both neo-classical trade theory and new trade theory have conducted a pioneering exploration and interpretation on this field from the factors of endowment differences, cost and technical differences, economies of scale and other direct factors concerning foreign trade competitiveness. But what led to the differences in these direct factors? Modern trade theory rarely studied the "Coupling Induction" mechanism of technological innovation-oriented resource allocation in the process of international competition. This leads to the existence of "gap" between the theory of modern foreign trade superiority and the new system theory. Therefore, this study takes this "gap" as the starting point, aiming to explore the coupling induction between the two and fill this "gap". The present study analyzed the role of the optimal allocation of resources driven by technological innovation in the process of international competition, hopefully to contribute to the field of theory and application of literature.

\section{Literature}

Coupling Induction, proposed by K. E. Weick (1976), refers to the association and interaction of the subsystems through the intermediation of the subsystems (or between the two or more elements). Vick (1976) introduced the Coupling Induction into social science by claiming that each interaction of the subsystems retains some identity and separateness and that their attachment may be circumscribed, infrequent, weak in its mutual affects, unimportant, and/or slow to respond. The "structural reform of the supply side" has rapidly become the focus and hot topic in the world and in 
various fields since 2015. Arthur Laffer (1983) proposed "Laffer Curve" stressed that "the demand in the economy will automatically adapt to the supply changes", that supply and demand is between the supply, rather than the demand to play a decisive role. Jia (2015) pointed out that the core connotation of the structural reform of the supply side lies in the "deepening the reform" to further liberate the productive forces and realize the transformation of the mechanism of a system engineering. You (2017) , based on the coupling theory, pointed out that the structural reform of the supply side in the field of foreign trade relies on "double creation" to stimulate new supply and create new demand. The focus of trade competition among countries is also focused on the heterogeneity of core technology and foreign trade products. This is consistent with the importance of the accumulation in the process of technological progress and technological innovation (Howells 1999; Achilladelis 2002; Cornish2013; Winham2014).

\section{Study Design}

Semi-logarithmic model (SLM)

On the basis of the extended export endogenous economic growth model, $\mathrm{H}$ Nari et al. proposed the Semi-logarithmic regression equation in the "Patterns of development: 1950-1970". As it is shown by formula (1)

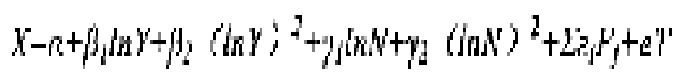

Where $\mathrm{X}$ is the dependent variable, represents a share of GDP; $\mathrm{Y}$ is the per capita national income, $\mathrm{N}$ is the total population, $\mathrm{F}$ is the net capital inflow, and $\mathrm{T}$ is the time. The semi-logarithmic model is shown in Figure 1.

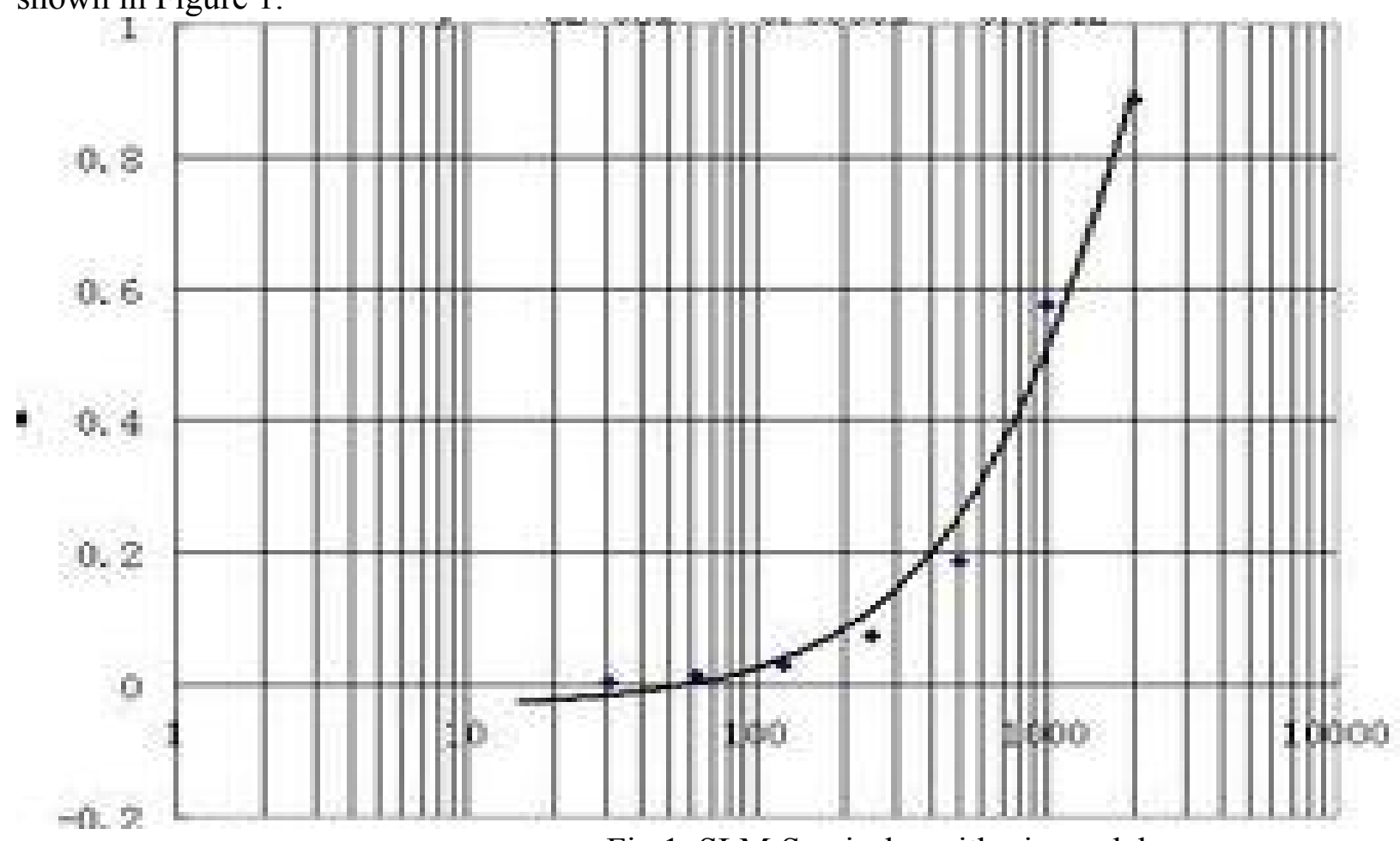

Fig 1. SLM:Semi - logarithmic model

The total export IX and the total exports of high-tech products IT are two variables. Variables, from the four dimensions of technological innovation-driven resource allocation, are divided into: innovative knowledge resources, innovative material resources, innovative human resources and innovative financial resources; each dimension specifically contains three sub-indicators. Based on the above explanatory variables and twelve indicators to explain the variables, the equations are established as follows.

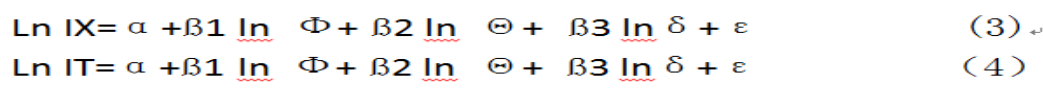


Among them, IX and IT are the explanatory variables, which denote the total export volume and the total export value of high-tech products respectively, $\alpha$ is constant term, $\beta$ is the regression coefficient, $\Phi, \Theta, \delta$, represent the sub-indicators respectively, and the $\varepsilon$ is random error.

\section{Coupling Induction and Regression Analysis}

Based on the above equation, this paper uses Stata12.0 to test the data of the above variables. The results of the regression analysis of the resource allocation and the upgrading of foreign trade structure of technological innovation drive are shown in Table 1.

Table 1. Regulatory results of technological innovation-driven resource allocation and upgrading of foreign trade structures

\begin{tabular}{|c|c|c|c|c|}
\hline Ian IX: & 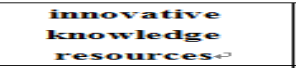 & $\begin{array}{l}\text { immovative } \\
\text { material } \\
\text { resonuces }\end{array}$ & $\begin{array}{l}\text { immorvative } \\
\text { Fowman } \\
\text { mesomices }\end{array}$ & $\begin{array}{l}\text { immovative } \\
\text { Timancial } \\
\text { pesomess }\end{array}$ \\
\hline$\infty$ & 3.701555 & $0.74504 \geq 5$ & $1.050 \geq 0 \geq 05$ & 3.658999 \\
\hline Im PP & $0.355005 \div \div 4$ & ד & 9 & $\rightarrow$ \\
\hline In FD. & -0.1359922 & $\leftrightarrow$ & $\Leftrightarrow$ & $\Rightarrow$ \\
\hline In TRE & $0.61000125 \neq \ldots$ & $\rightarrow$ & 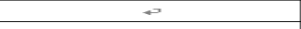 & $\rightarrow$ \\
\hline 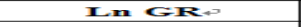 & $\leftrightarrow$ & $0.0 \geq 15255 \div=\infty$ & 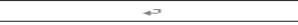 & $\rightarrow$ \\
\hline Im C C : & $\Leftrightarrow$ & -0.025636220 & 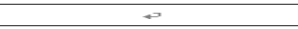 & $\rightarrow$ \\
\hline IAn SIR $\rightarrow$ & $\leftrightarrow$ & $2.6591002=-1$, & $\leftrightarrow$ & $\rightarrow$ \\
\hline I.m $\mathrm{CC}=4$ & $\rightarrow$ & 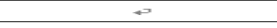 & $0.68215541 \div \div$ & 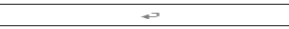 \\
\hline Im IRS: & $\rightarrow$ & 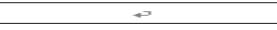 & 0.320005624 & $\rightarrow$ \\
\hline I.n ssin & $\rightarrow$ & 9 & $0.61022231 \neq+4$ & $\rightarrow$ \\
\hline Im GE & $\Rightarrow$ & $\rightarrow$ & 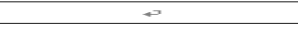 & 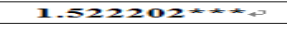 \\
\hline $\operatorname{In} T<x$ & $\rightarrow$ & 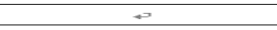 & $\rightarrow$ & $0.4215563 \neq \div$ \\
\hline In RE & $\rightarrow$ & $\rightarrow$ & $\rightarrow$ & 0.2516633 \\
\hline $\operatorname{adil}-\mathbf{K} Z$ & 0.98sza & 0.99254 & 0.99214 & 0.9023 \\
\hline F-statistive & 100.220 & 91.63 & 233.01. & $80-32$ \\
\hline Probar-statistied & 0.0000 & 0.0000 & 0.0000 & 0.0000 \\
\hline \multicolumn{5}{|c|}{ 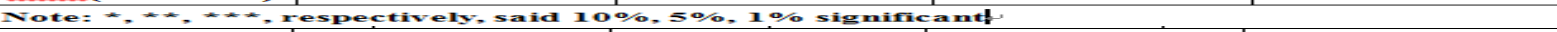 } \\
\hline Ln TI: & $\begin{array}{l}\text { inmovative } \\
\text { knowledge } \\
\text { resources }\end{array}$ & $\begin{array}{l}\text { inmovative } \\
\text { material } \\
\text { resources }\end{array}$ & $\begin{array}{l}\text { innovative } \\
\text { human } \\
\text { resources }\end{array}$ & $\begin{array}{l}\text { innovative } \\
\text { financial } \\
\text { resources }\end{array}$ \\
\hline 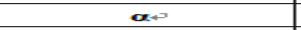 & 2.7012520 & 0.5450021 & 1.156852610 & 2.620993 \\
\hline In PP: & $0.345975 * \ldots$ & $\rightarrow$ & $\rightarrow$ & $\rightarrow$ \\
\hline In KD: & -0.10597520 & 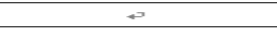 & $\rightarrow$ & 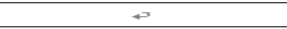 \\
\hline In TR: & $0.51011128 \div \ldots$ & 0 & 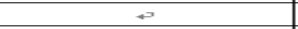 & 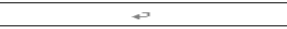 \\
\hline In GR & 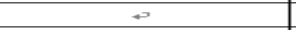 & $0.4885501 \div \div$ & 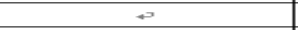 & a \\
\hline In UCe & $\rightarrow$ & -0.00061629 & 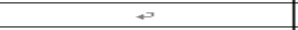 & $\infty$ \\
\hline In SR & $\rightarrow$ & $2.8591008 \div \cdots$ & 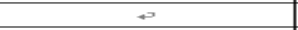 & 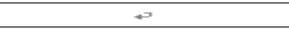 \\
\hline In CG: & $\rightarrow$ & 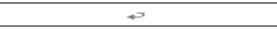 & $0.88215541 \div \neq$ & 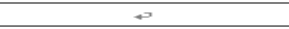 \\
\hline Ln RS & $\infty$ & $\infty$ & 0.120007720 & $\infty$ \\
\hline In SS: & 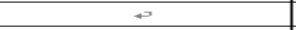 & $\rightarrow$ & $0.81022582 \cdots \cdots$ & $\infty$ \\
\hline In GE & 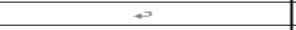 & s & 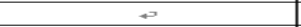 & $1.02120388 \div \neq=6$ \\
\hline In TC & $\rightarrow$ & $\infty$ & $\infty$ & $0.5215578 * \ldots$ \\
\hline Ln RE & $\infty$ & $\infty$ & 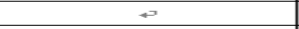 & 0.1516678 \\
\hline $\operatorname{adi}-k 2$ & 0.9752 & 0.9825 & 0.9921 & 0.9973 \\
\hline F-statistic & 99.22 & 101.64 & 203.01 & 91.37 \\
\hline Prob(F-statistic) & 0.0000 & 0.0000 & 0.0000 & 0.0000 \\
\hline
\end{tabular}

According to the results of empirical regression in Table 1, the overall fitting effect of innovative knowledge resources, innovative material resources, innovative human resources and innovative financial resources is better than that of total export IX, and the R2 values of each dimension adjustment are more than 95\% F-statistic indicating that each equation has a high significance. According to the parameters of each dimension, the results of the correlation estimation are as follows: From the dimension of the knowledge resource, the parameters of the patent application, the R \& D activities and the scientific and technological achievements are 0.355995, -0.1359922 and 0.61000125 respectively. The patent application and the scientific and technological achievements are at $5 \%$ and $1 \%$ of the level, while its parameters are positive, indicating that both of them and exports IX are with a positive correlation. $\mathrm{R} \& \mathrm{D}$ activity parameters are negative, indicating that this indicator has a negative correlation with foreign trade exports, but not at $5 \%$ and $1 \%$ level, so the negative impact is not significant. From the perspective of innovative material resources, the parameters of government research institutes, universities and social research institutions are $0.6215255,-0.02563622$ and 2.6591002 respectively. Government research institutes and social 
research institutions at $5 \%$ and $1 \%$ of the level of significant, while its parameters are positive, indicating that both of them and export IX is a positive correlation.

The Coupling Induction between Technological Innovation-Oriented Resource Allocation and Trade Growth is shown by the following figure2.

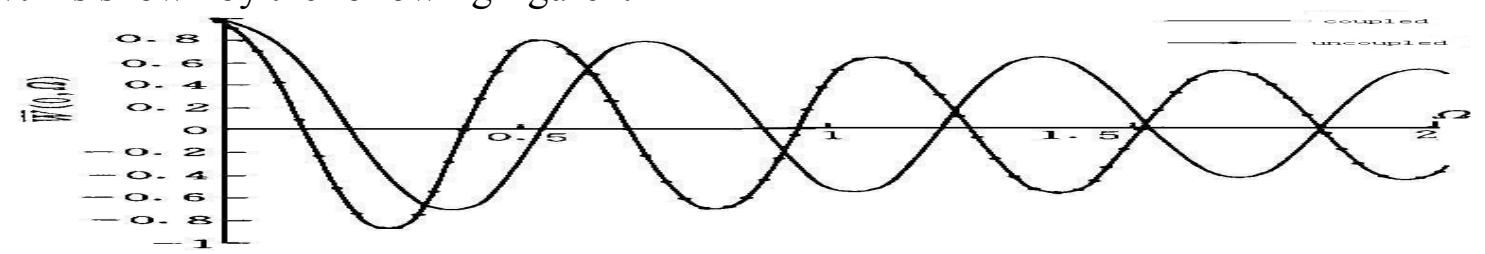

Fig 2. Coupling Induction between Technological Innovation Resource Allocation and Trade

\section{Conclusions}

This paper adopts the econometric method to analyze the Coupling Induction between the technological innovation-driven resource allocation and the transformation and upgrading of foreign trade. From the empirical results can it be concluded that the innovative driving force of resource allocation optimization can be a decent means to stimulate the regional foreign trade transformation and structural upgrading. Especially the social research institutions and government research funding have a relatively significant positive impact, these two indicators of investment can bring a substantial increase in exports. Based on the above empirical conclusions and analysis, this study puts forward some countermeasures and suggestions. It is advisable to attach importance to the division of labor to bring professional and efficiency. The combination of resource allocation optimization and technological innovation drive lies in the smoothness of factor resource flow in technological innovation activities. Therefore, aiming to solve the asymmetry problem of technological innovation information, to achieve the rapid dissemination of various types of innovative technology information and efficient use, it is advisable to promote all kinds of technological innovation and resource allocation and integration, so that innovative elements of resources in the field of foreign trade can achieve free flow, leading to a strong regional technological innovation system in trade.

\section{Acknowledgements}

This work was financially supported by the Guangdong Provincial Philosophy and Social Sciences " Thirteenth Five-Year Plan" 2016 annual academic projects (Guangdong foreign trade "supply side reform" driven development path analysis, project number GD16XYJ30) and Guangzhou philosophy and social science development "Thirteenth Five-Year Plan" 2017 annual co-construction project (supply side structural reform of the Guangzhou foreign trade enterprises under the resource allocation and technological innovation-driven path research, project number 2017GZGJ20); Guangzhou College of Business and Technology 2016 issue (Grant No.KA201602); Online MOOC demonstration course(Grant No. ZL20161226); the 2016 project of Northeast Normal University (Grant No.2016NNUP04), and Guangdong Vocational Education Information Research Associate 2016 - 2017 annual project issues("Internet + Vocational Education" Business English Course Construction Information Promotion Practice, Grant No. YZJY161739)

\section{References}

[1] KE.Weick . Educational Organizations as Loosely Coupled Systems [J] Administrative Science Quarterly.1976.21:1-19.

[2] Howells .J intermediation and the role of intermediaries in technological innovation[J]. ResearchPolicy,2006

[3] Grossman, G.M. and Helpman, E.rade; Technological innovation and Growth[M]. Princeton, Woodrow Wilson School-Public and International Affairs.1989; 
[4] You Yucong. Comparative Advantage, Transaction Cost and Empirical Study on the Driving Path of Guangdong's Foreign Trade System Technological innovation [J]. Social Sciences, 2016

[5] You Yu-cong, Yi Luxia. An Technological innovation Research on Education Statistical Work in In Big Data Era [C] .2016ICEMS Proceedings （ISTP Compendex）;

[6] Zhang Yinyin, Deng Ling. Technological innovation to drive the transformation and upgrading of traditional industries to strategic emerging industries: mechanism and path $[\mathrm{J}]$. Economic system reform, 2016;

[7] Hong Yinxing. Several important concepts abouttechnological innovation-driven and innovative economy [J]. Mass, 2011; 